

RemoteSensing.SPIEDigitalLibrary.org

\title{
Fusion of satellite-based imager and sounder data to construct supplementary high spatial resolution narrowband IR radiances
}

Elisabeth Weisz

Bryan A. Baum

W. Paul Menzel 


\title{
Fusion of satellite-based imager and sounder data to construct supplementary high spatial resolution narrowband IR radiances
}

\author{
Elisabeth Weisz, * Bryan A. Baum, and W. Paul Menzel \\ University of Wisconsin-Madison, Space Science and Engineering Center, Madison, \\ Wisconsin, United States
}

\begin{abstract}
Polar-orbiting weather satellite platforms generally include an imager and a sounder. With a data fusion method that uses these sensors, we demonstrate the ability to construct infrared (IR) absorption narrowband radiances at imager resolution. While a sensor such as MODIS has multiple IR absorption bands, the current visible infrared imaging radiometer suite (VIIRS) imager has only IR window bands. We show fusion results for IR radiances at $4.52 \mu \mathrm{m}\left(\mathrm{CO}_{2}\right)$, $6.72 \mu \mathrm{m}\left(\mathrm{H}_{2} \mathrm{O}\right)$, and $13.94 \mu \mathrm{m}\left(\mathrm{CO}_{2}\right)$ by comparing MODIS observed and constructed radiances for these bands. Both regional and global results are analyzed, with radiance differences tending to be fairly low and unbiased. Similar bands are constructed from VIIRS and CrIS data, with regional and global results shown. With this approach, it will be possible to improve continuity in derived cloud products over the generations of polar-orbiting weather satellite sensors and continue applications that require IR absorption bands. () The Authors. Published by SPIE under a Creative Commons Attribution 3.0 Unported License. Distribution or reproduction of this work in whole or in part requires full attribution of the original publication, including its DOI. [DOI: 10 .1117/1.JRS.11.036022]
\end{abstract}

Keywords: satellite remote sensing; data fusion; multisensor; infrared spectral range; high spatial resolution imager; high spectral resolution sounder.

Paper 170505 received Jun. 8, 2017; accepted for publication Aug. 17, 2017; published online Sep. 11, 2017.

\section{Introduction}

Polar-orbiting weather satellite platforms generally include both a high spatial resolution imager, with pixel spatial resolution on the order of $1 \mathrm{~km}$, and a high spectral resolution (or hyperspectral) infrared (IR) sounder, with fields of view (FOVs) of about $14 \mathrm{~km}$. The imagers are designed to take measurements for a limited set of narrow wavelength bands at visible through IR wavelengths. The imager data are used, for example, to develop operational aerosol and cloud properties. The sounder measurements are generally used to infer profiles at high vertical resolution of temperature, water vapor $\left(\mathrm{H}_{2} \mathrm{O}\right)$, and ozone $\left(\mathrm{O}_{3}\right)$, and also to infer surface, trace gas, and cloud properties. Hyperspectral sounders cover a spectral range from $\sim 3.6$ to $15.5 \mu \mathrm{m}$ (Fig. 1). As it will be shown in the following discussion, there are differences in the satellite imager/sounder measurements across platforms. Some imagers lack absorbing IR bands that are necessary to obtain accurate products such as total column precipitable $\mathrm{H}_{2} \mathrm{O}$ and cloud properties (e.g., cloud-top height and thermodynamic cloud phase). The objective of our effort is to develop a data fusion methodology based on imager-sounder pairs to construct the missing IR absorption bands, which then can enable the derivation of more consistent atmospheric products.

The moderate-resolution imaging spectroradiometer (MODIS) makes measurements at $1 \mathrm{~km}$ (or better) spatial resolution in bands usually attributed to both imagers and sounders. The MODIS IR bands were selected to match those of the 20-channel high-resolution infrared radiometer sounder (HIRS). With the first launch of MODIS on the NASA Terra platform in December 1999 and subsequently on the NASA Aqua platform in May 2002, measurements have been obtained for 36 bands ranging from 0.4 to $14.2 \mu \mathrm{m}$. A major advantage afforded

*Address all correspondence to: Elisabeth Weisz, E-mail: elisabeth.weisz@ ssec.wisc.edu 
(a)

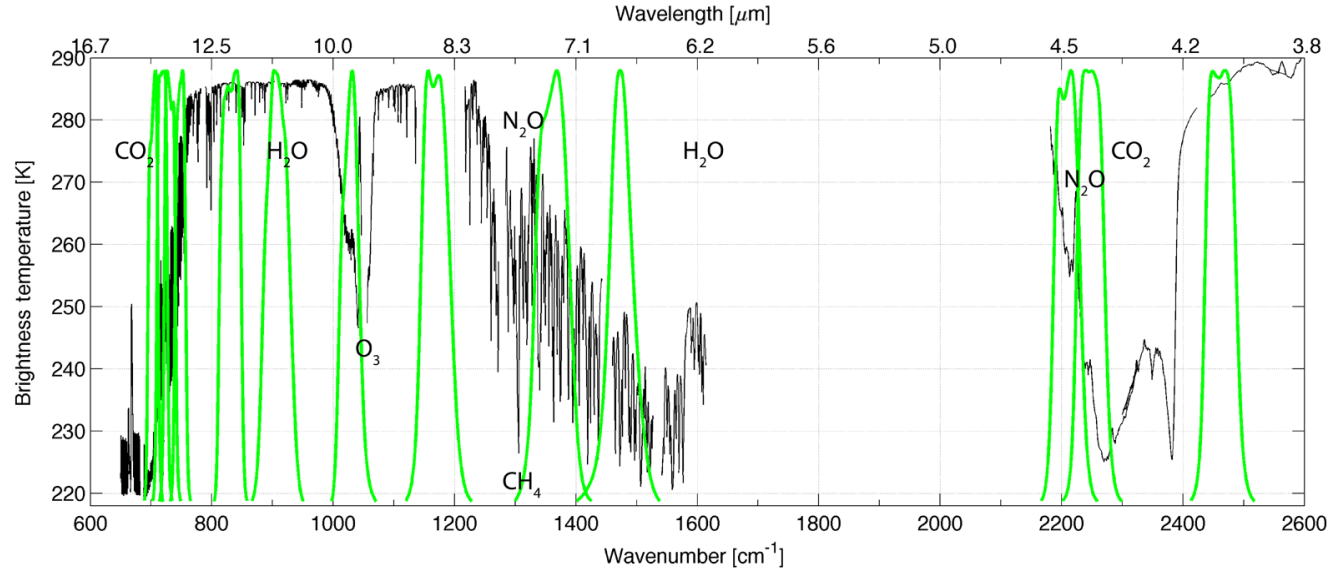

(b)

CrIS BT spectrum and VIIRS spectral response functions

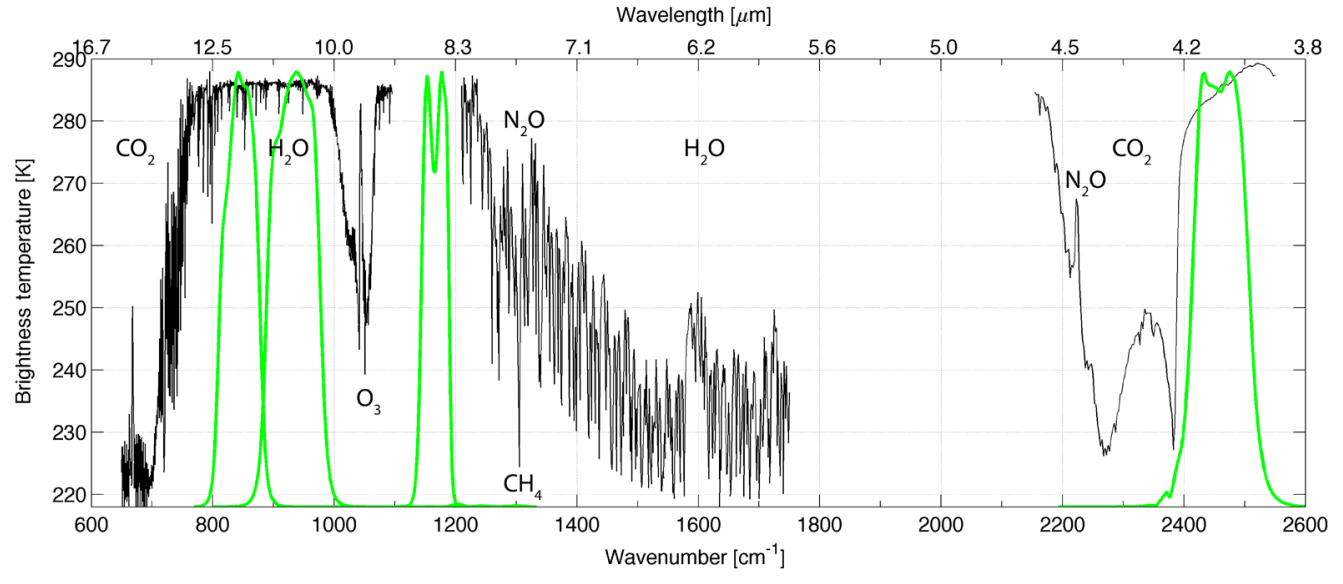

Fig. 1 (a) AIRS and (b) CrIS infrared brightness temperature spectrum (black) with main absorbers indicated, and the (a) MODIS and (b) VIIRS SRFs (green) superimposed. The SRFs are scaled to fit the brightness temperature range.

by the MODIS sensors is that they provide measurements at high spatial resolution in both the IR $\mathrm{H}_{2} \mathrm{O}($ at $6.7 \mu \mathrm{m})$ and carbon dioxide- $\left(\mathrm{CO}_{2}\right)(15 \mu \mathrm{m})$ sensitive bands. The IR MODIS bands are listed in Table 1 and the MODIS spectral response functions (SRF) for bands 23 to 36 (excluding band 26, which is at $1.38 \mu \mathrm{m}$ ) are shown in Fig. 1(a). While the Terra platform did not include a separate sounder, the Aqua platform included a hyperspectral sounder called the atmospheric infrared sounder (AIRS).

The current generation polar-orbiting imager is the visible infrared imaging radiometer suite (VIIRS). The companion sounder is called the cross-track interferometer sounder (CrIS). VIIRS has several major improvements when compared to the earlier imagers (e.g., better signal-tonoise characteristics, higher spatial resolution, oversampling so that the spatial resolution stays fairly constant across the scan). However, VIIRS does not have any spectral bands sensitive to $\mathrm{CO}_{2}, \mathrm{H}_{2} \mathrm{O}$, or $\mathrm{O}_{3}$ in the atmosphere; VIIRS has only IR window bands at $8.5,11$, and $12 \mu \mathrm{m}$ (Table 1). The VIIRS SRFs for these bands are superimposed over a sample CrIS spectrum in Fig. 1(b). Without a single IR $\mathrm{CO}_{2}$ - or $\mathrm{H}_{2} \mathrm{O}$-sensitive band, the MODIS-like cloud-top height/ pressure/temperature and IR thermodynamic phase algorithms cannot be transitioned to VIIRS because of a fundamental loss of information. ${ }^{1}$ Heidinger et al. ${ }^{1}$ employed an optimal estimation approach using IR channels to infer cloud-top height. This study clearly showed that supplementing the IR window bands with just a single sounding band located at $13.3 \mu \mathrm{m}$ improved the analysis of optically thin ice clouds over that from use of only IR window bands.

The same fusion approach can be applied to any other satellite-based imager/sounder pair, for example, advanced very high-resolution radiometer (AVHRR) and HIRS. AVHRR, which has 
Weisz, Baum, and Menzel: Fusion of satellite-based imager and sounder data to construct...

Table 1 MODIS and VIIRS IR bands.

\begin{tabular}{|c|c|c|c|c|}
\hline \multicolumn{2}{|r|}{ MODIS IR bands } & \multicolumn{2}{|r|}{ VIIRS IR bands } & \multirow[b]{2}{*}{ Primary use } \\
\hline Band & Central wavelength $(\mu \mathrm{m})$ & Band & Central wavelength $(\mu \mathrm{m})$ & \\
\hline 20 & 3.75 & & & Surface and cloud properties \\
\hline 21 & 3.96 & & & Fire detection \\
\hline 22 & 3.96 & & & Surface and cloud properties \\
\hline 23 & 4.05 & M13 & 4.05 & Atmospheric temperature \\
\hline 24 & 4.47 & & & Atmospheric temperature \\
\hline 25 & 4.52 & & & Atmospheric temperature \\
\hline 27 & 6.72 & & & $\mathrm{H}_{2} \mathrm{O}$ \\
\hline 28 & 7.33 & & & $\mathrm{H}_{2} \mathrm{O}$ \\
\hline 29 & 8.55 & M14 & 8.55 & Surface and cloud properties \\
\hline 30 & 9.73 & & & $\mathrm{O}_{3}$ \\
\hline 31 & 11.03 & M15 & 10.76 & Surface and cloud properties \\
\hline 32 & 12.02 & M16 & 12.01 & Surface and cloud properties \\
\hline 33 & 13.34 & & & Cloud properties \\
\hline 34 & 13.64 & & & Cloud properties \\
\hline 35 & 13.94 & & & Cloud properties \\
\hline 36 & 14.23 & & & Cloud properties \\
\hline
\end{tabular}

only three IR window bands, has been the imager on the NOAA polar-orbiting platforms since 1978. The construction of additional bands for AVHRR based on HIRS would support climate studies by creating decadal sets of various parameters in a consistent fashion that are based on the same information content. AVHRR can also be paired with infrared atmospheric sounding interferometer (IASI), the hyperspectral sounding instrument on the European Metop-satellites. ${ }^{2}$ IASI provides a continuous spectrum (i.e., without any gaps) in the same IR range as AIRS and CrIS.

The basis of our approach is presented in Ref. 3, where a 13.3- $\mu \mathrm{m}$ band is constructed from the fusion of MODIS plus AIRS on Aqua and VIIRS plus CrIS on the Suomi-National Polarorbiting Partnership platform. In their approach, a high spatial resolution $13.3-\mu \mathrm{m} \mathrm{CO}_{2}$ band is constructed for MODIS at 1-km spatial resolution by combining the high spatial resolution MODIS IR window data at 11 and $12 \mu \mathrm{m}$ (the so-called split-window bands) with lower spatial resolution $13.3-\mu \mathrm{m}$ data derived from AIRS. The atmospheric contribution from $\mathrm{CO}_{2}$ is uniform enough so AIRS measurements for a larger FOV can be combined with the MODIS IR window measurements to create a $13.3-\mu \mathrm{m}$ measurement at $1-\mathrm{km}$ spatial resolution.

In this study, we explore the possibility of providing other IR bands as well. We demonstrate that MODIS band $25(4.5 \mu \mathrm{m})$, band $27(6.7 \mu \mathrm{m})$, and band $35(13.9 \mu \mathrm{m})$ can be constructed by combining MODIS and AIRS, and VIIRS and CrIS data. While MODIS already has these spectral IR channels of interest (Table 1), it serves as an invaluable platform for testing the data fusion methodology for multiple IR wavelengths and describing the uncertainty in the newly constructed radiances.

After describing the satellite platforms and their imager/sounder payloads, we will give a brief summary of the data fusion methodology in Sec. 2. Results are shown and discussed in Sec. 3, which include comparisons between measured and constructed MODIS radiances, both for a granule and for a day of global data. Also shown in Sec. 3 are results from VIIRS + CRIS, again for a selected granule as well as on a global scale. Section 4 summarizes the study and suggests future work. 


\section{Satellite Payload and Fusion Methodology}

\subsection{Satellites and Instruments}

\subsubsection{Aqua platform: MODIS and AIRS}

The MODIS sensor is a 36-band whiskbroom scanning radiometer on the NASA Terra and Aqua platforms. ${ }^{4}$ The Terra platform is in a daytime descending orbit with an equatorial crossing of 1030 local solar time (LST). The Aqua platform maintains an altitude of $705 \mathrm{~km}$ and is in a daytime ascending orbit at 1330 LST. For more specifications, see Table 2. The MODIS collection 6 (C6) cloud products ${ }^{5}$ incorporate a number of both calibration and retrieval methodology improvements for the inference of cloud-top temperature and pressure and the discrimination of cloud thermodynamic phase using IR bands. The cloud-top parameters (height, pressure, temperature, and IR phase) are provided at 1 - and 5-km spatial resolutions.

The AIRS ${ }^{6,7}$ on the Aqua satellite is a high spectral resolution (wavenumber to resolution ratio of 1200) grating spectrometer with 2378 spectral channels in the wavelength regions of 3.7 to $4.61 \mu \mathrm{m}, 6.2$ to $8.22 \mu \mathrm{m}$, and 8.8 to $15.4 \mu \mathrm{m}$ [a sample spectrum is shown in Fig. 1(a)]. AIRS radiances enable the derivation of vertical profiles of atmospheric temperature and $\mathrm{H}_{2} \mathrm{O}$ from the earth's surface to the top of the atmosphere (TOA) with a horizontal resolution of $13.5 \mathrm{~km}$ at nadir.

\subsubsection{Suomi-NPP platform: VIIRS and CrIS}

The main features of VIIRS and CrIS are listed in Table 2. The Suomi-NPP platform launched on October 28, 2011 maintains an altitude of $824 \mathrm{~km}$ and has an equatorial crossing of 1330 UTC. The VIIRS sensor ${ }^{8}$ is a 22-band scanning radiometer that has 16 bands at $750-\mathrm{m}$ resolution (medium resolution or $\mathrm{M}$ bands), 5 bands at 375-m resolution (imaging bands or I bands), and a day/night band. Only the $M$ bands are used for this study (Table 1).

The companion sounder to VIIRS, CrIS, ${ }^{9}$ is a Fourier transform spectrometer that provides measurements for 1305 spectral channels over three wavelength ranges [Fig. 1(b)]: LWIR (9.14 to $15.38 \mu \mathrm{m}$ ); MWIR (5.71 to $8.26 \mu \mathrm{m})$; and SWIR (3.92 to $4.64 \mu \mathrm{m})$. CrIS scans a 2200-km swath width, with 30 Earth-scene views, each consisting of nine FOVs, arranged in a $3 \times 3$ array of 14-km-diameter spots (nadir spatial resolution). A primary purpose for CrIS is the determination of high-resolution, three-dimensional temperature, pressure, and moisture profiles.

\subsection{Data Fusion}

The construction of high spatial resolution IR narrowband radiances is briefly described in this section; further details are provided in Ref. 3. The method consists of two steps: (1) performing a nearest neighbor search using the k-d tree algorithm on both high spatial and low spatial resolution split-window imager radiances, and (2) averaging the convolved sounder radiances (at low spatial resolution) for the nearest neighbors selected in (1) of for each imager pixel. These two steps are shown in Figs. 2(a) and 2(b).

To reduce confusion between the imager and sounder spatial resolution, we use "pixel" for the imager and "FOV" for the sounder. Figure 2(a) shows the methodology of the first step, the

Table 2 MODIS, AIRS, VIIRS, and CrIS instrument specifications.

\begin{tabular}{llcccc}
\hline \hline Instrument & $\begin{array}{l}\text { IR spectral } \\
\text { range }(\mu \mathrm{m})\end{array}$ & $\begin{array}{c}\text { \# of IR bands/ } \\
\text { channels }\end{array}$ & $\begin{array}{c}\text { Swath width } \\
(\mathrm{km})\end{array}$ & $\begin{array}{c}\text { Scanning } \\
\text { angle }(\mathrm{deg})\end{array}$ & $\begin{array}{c}\text { Nadir FOV } \\
\text { size }(\mathrm{km})\end{array}$ \\
\hline MODIS & 3.6 to 14.4 & 16 & 2300 & \pm 55 & 1 \\
AIRS & 3.7 to 15.4 & 2378 & 1650 & \pm 49.5 & 13.5 \\
VIIRS & 3.6 to 12.5 & 7 & 3000 & \pm 56 & 0.75 \\
CrIS & 4.6 to 15.4 & 1305 & 2200 & \pm 50 & 14 \\
\hline \hline
\end{tabular}


(a)

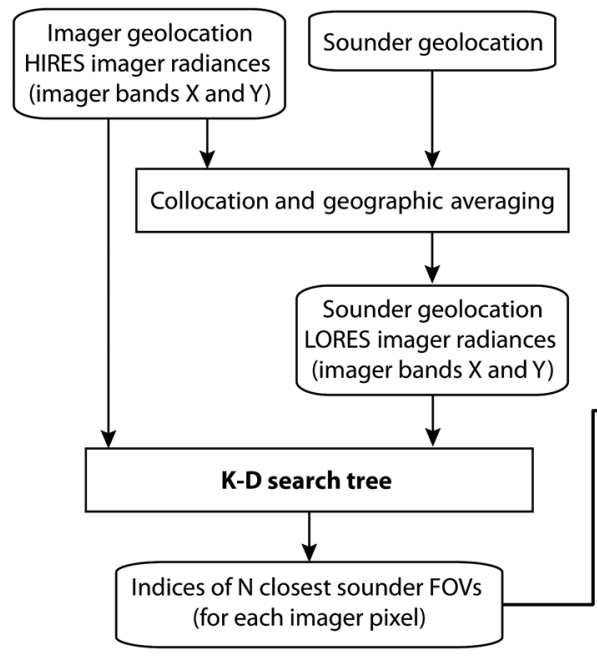

(b)

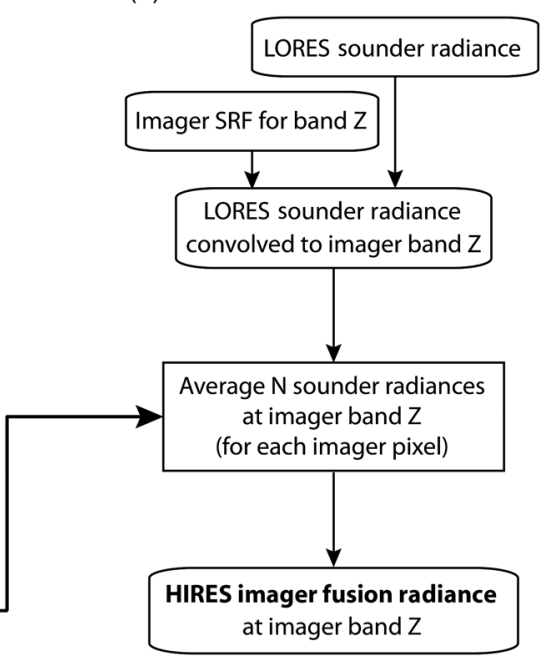

Fig. 2 (a) The process for creating a multidimensional search tree using high spatial resolution (HIRES) and low spatial resolution (LORES) imager radiance and geolocation information. (b) Application of the $k-d$ tree neighbor indices to LORES sounder radiances. Bands $X$ and $Y$ refer to the split-window bands, and $Z$ refers to the imager band to be constructed via the fusion process. $\mathrm{SRF}$ refers to the spectral response function.

k-d tree search, which finds the $N$ sounder FOVs that best match each imager pixel. For the results shown here, $N$ is set to 5 . The k-d tree algorithm ${ }^{3,10-12}$ is used to provide the closest matching FOVs in the training data set (here, low spatial resolution imager data) to each pixel in a query data set (here, high spatial resolution imager data). Specifically, the inputs to the k-d tree are the splitwindow 11 and $12 \mu \mathrm{m}$ imager radiances at both the pixel and FOV spatial resolution; for the latter, the imager radiances, geographically collocated to each sounder FOV, have been averaged. The corresponding imager and sounder latitude and longitude values are used as additional predictors. The k-d tree input data has therefore npix (number of pixels in an imager granule) and four predictors (two bands of radiances, as well as latitudes and longitudes). It should be emphasized that the k-d tree search is solely based on imager radiances (at the pixel resolution and averaged over the FOV resolution) and not on sounder radiance information. To be clear, only the split-window bands, i.e., MODIS bands 31 and 32 and VIIRS bands M15 and M16, are used in the k-d tree application to a granule. The outcome of the first step is a matrix of dimension $n$ pix $\times N$ containing the indices of the $N$ sounder FOVs that are closest in space and best match the measured imager IR radiances.

For the second step [Fig. 2(b)], sounder radiances for each FOV are convolved with the SRF for the band to be constructed at imager pixel resolution. Thus, high spectral resolution sounder radiances are reduced to match narrowband (i.e., imager-like) radiances while retaining the sounder spatial resolution. The mean of the convolved radiances for the $N$ neighbors (associated with the indices found in the first step) is computed. This process is repeated for every imager pixel in the granule.

Figures 3(a)-3(c) shows how close the selected sounder FOVs (in blue) are located to three selected imager pixels (in red) in a MODIS granule, and Fig. 3(d) shows the average distance between each imager pixel and the five sounder FOVs for an entire granule. Note that within the scan boundary of the sounder, which is always less than that of the imager, the average distance is quite low. As expected the distance increases outside of the sounder scan limit, which provides an indication of the expected constructed radiance quality as will be discussed in the next section.

\section{Imager/Sounder Fusion Results}

\subsection{MODIS and AIRS Results}

Any MODIS IR band can be reconstructed using the fusion methodology as outlined in the previous section, assuming that the sounder has the necessary information content. Our goal 
Weisz, Baum, and Menzel: Fusion of satellite-based imager and sounder data to construct...

(a) MODIS FOV 970/2 (Lat/Lon 35.5/-8.2)

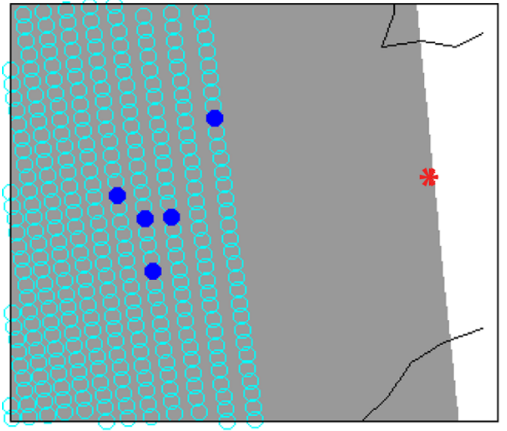

(c) MODIS FOV 1480/325 (Lat/Lon 39.4/-17.7)



(b) MODIS FOV 327/223 (Lat/Lon 29.3/-13.7)

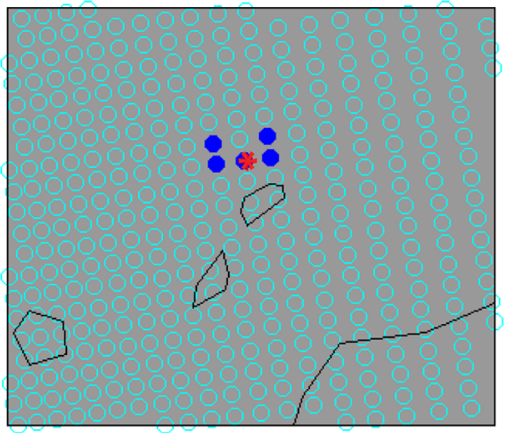

(d) Imager/Sounder distance [km]

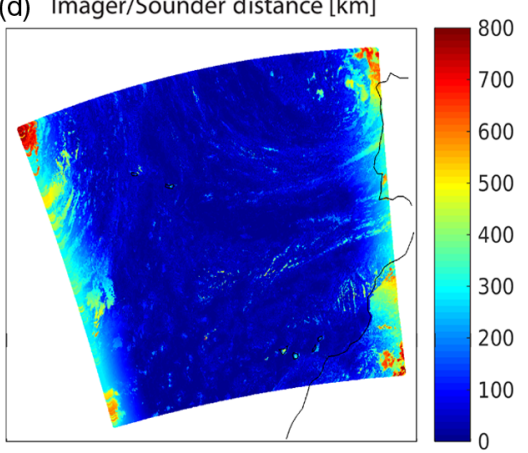

Fig. 3 (a-c) Selected MODIS pixels (red asterisk) and corresponding AIRS sounder neighbors (blue dots) as provided by the $\mathrm{k}-\mathrm{d}$ tree search. The gray background and the cyan circles represent the MODIS granule coverage and the AIRS sounder FOVs, respectively. (d) Average distance (in kilometers) of sounder FOVs from each imager pixel. Results are shown for the MODIS granule at 1435 UTC on April 17, 2015.

is to determine the degree to which MODIS-like absorption band radiances can be constructed for the VIIRS sensor. For evaluation, the Aqua MODIS SRFs for three bands are applied to the sounder radiances: band $25(4.52 \mu \mathrm{m})$, band $27(6.72 \mu \mathrm{m})$, and band $35(13.94 \mu \mathrm{m})$. As outlined above and in Fig. 2, the mean of the convolved sounder radiances for five neighbors is computed and reported for each imager pixel resulting in a synthesized imager band at the imager's high spatial resolution.

Figure 4 shows MODIS radiances for bands 31 and 32 (i.e., the bands used in the k-d tree search), whereas Fig. 5 shows the AIRS radiances convolved with the Aqua MODIS SRFs for MODIS bands 25, 27, and 35 (i.e., bands to be constructed). This case describes a 5-min MODIS granule, acquired at 1435 UTC on April 17, 2015, located off the coast of Morocco and Portugal, and the collocated AIRS granules 145 and 146. The outlines of the MODIS granule are shown in Fig. 5 to illustrate the differences in imager and sounder swath widths. To create the new fusion bands 25, 27, and 35, the radiance shown in Fig. 5 is averaged for the five neighbors, found by applying a k-d tree search on the radiance and geolocation values shown in Fig. 4.

(a) MODIS B31 radiance $\left[\mathrm{W} \mathrm{m}^{-2} \mathrm{sr}^{-1} \mu \mathrm{m}\right]$

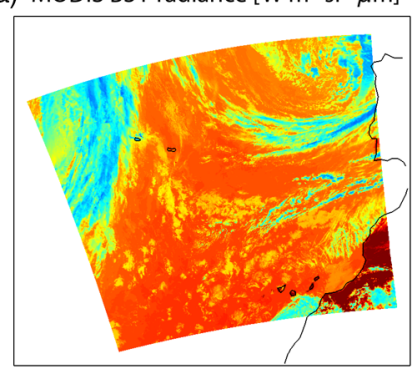

(b)

(b) MODIS B32 radiance [W $\left.\mathrm{m}^{-2} \mathrm{sr}^{-1} \mu \mathrm{m}\right]$
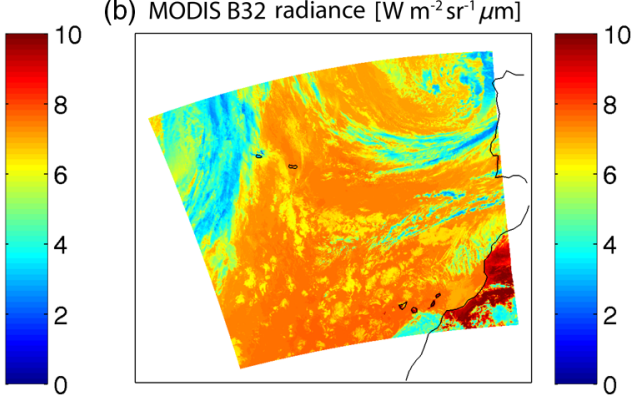

Fig. 4 MODIS observed radiances for (a) band 31 and (b) band 32 at 1435 UTC on April 17, 2015. 
Weisz, Baum, and Menzel: Fusion of satellite-based imager and sounder data to construct...

(a) AIRS radiance $\left[\mathrm{W} \mathrm{m}^{-2} \mathrm{sr}^{-1} \mu \mathrm{m}\right]$ at $\mathrm{B} 25$

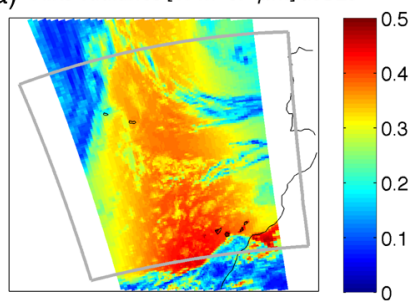

(b) AIRS radiance $\left[\mathrm{W} \mathrm{m}^{-2} \mathrm{sr}^{-1} \mu \mathrm{m}\right]$ at B27

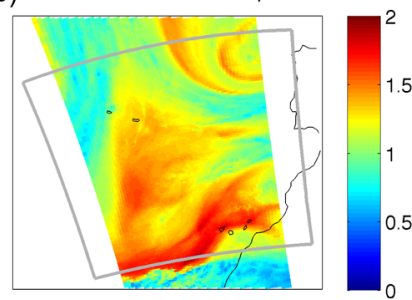

(c) AIRS radiance $\left[\mathrm{W} \mathrm{m}^{-2} \mathrm{sr}^{-1} \mu \mathrm{m}\right]$ at $\mathrm{B} 35$



Fig. 5 AIRS radiances convolved with the SRFs for MODIS bands (a) 25, (b) 27, and (c) 35 for AIRS granules 145 and 146 on April 17, 2015. The outline of the corresponding Aqua MODIS granule (acquired at 1435 UTC) is shown in gray.

The fusion results, as well as the original observed MODIS radiance and the differences of "observed minus fusion" radiance for the three bands are shown in Fig. 6. The corresponding means and root mean square errors (in radiance and brightness temperature units) of the differences for the full granule as well as the smaller region within the sounder swath are given in Table 3.

As seen in Fig. 6 and Table 3, the differences are largest at the edge of the granule, where fewer sounder FOVs are available in close vicinity [as shown in Fig. 3(a)]. As the scan angle increases, the amount of the atmosphere observed by the sensor increases, leading to an increase in atmospheric absorption and hence lower radiances. This is generally described as "limb darkening." Since the sounder granule does not entirely cover the imager swath due to its smaller swath width, the fusion process will not correctly reproduce the atmospheric absorption and may also not completely capture cloud features. At high scan angles, the differences between observed and constructed radiances tend to be larger than within the area encompassed by the both the sounder and imager. For example, it is most evident for band 27 [Fig. 6(b)] in

(a)

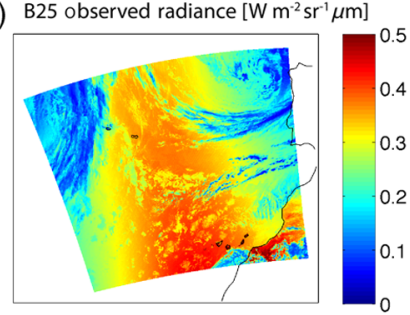

(b)



(c)

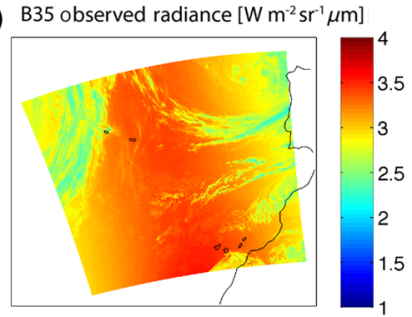

B25 fusion radiance $\left[\mathrm{W} \mathrm{m}^{-2} \mathrm{sr}^{-1} \mu \mathrm{m}\right]$

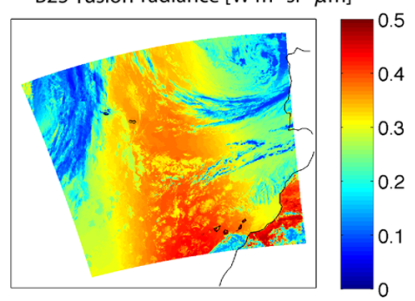

B27 fusion radiance $\left[\mathrm{W} \mathrm{m}^{-2} \mathrm{sr}^{-1} \mu \mathrm{m}\right]$

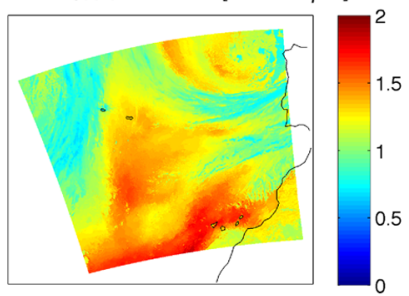

B35 fusion radiance $\left[\mathrm{W} \mathrm{m}^{-2} \mathrm{sr}^{-1} \mu \mathrm{m}\right]$

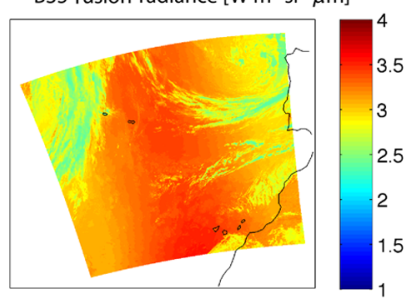

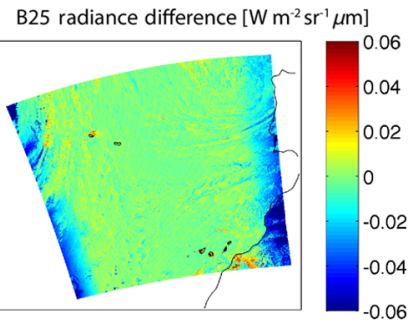

B27 radiance difference $\left[\mathrm{W} \mathrm{m}^{-2} \mathrm{sr}^{-1} \mu \mathrm{m}\right]$



B35 radiance difference $\left[\mathrm{W} \mathrm{m}^{-2} \mathrm{sr}^{-1} \mu \mathrm{m}\right]$

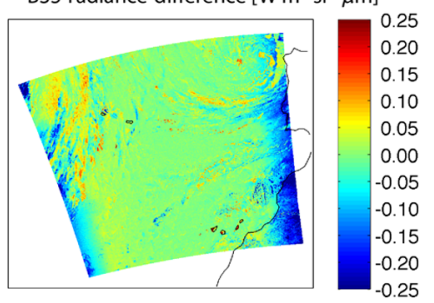

Fig. 6 Original (observed) MODIS radiance (left), newly constructed fusion radiance (middle), and the "observed minus fusion" radiance differences (right) for MODIS bands 25, 27, and 35 in (a-c), respectively. 
Table 3 Mean and RMS of "observed minus fusion" radiance (and brightness temperature) differences for the full MODIS granule (1435 UTC, April 17, 2017). Values for the region within the sounder swath are in parentheses.

\begin{tabular}{|c|c|c|c|c|c|c|}
\hline & \multicolumn{2}{|c|}{ Band 25} & \multicolumn{2}{|c|}{ Band 27} & \multicolumn{2}{|c|}{ Band 35} \\
\hline & Mean & RMS & Mean & RMS & Mean & RMS \\
\hline $\begin{array}{l}\text { Radiance } \\
\left(\mathrm{Wm}^{-2} \mathrm{sr}^{-1} \mu \mathrm{m}\right)\end{array}$ & $\begin{array}{l}-0.003 \\
(0.012)\end{array}$ & $\begin{array}{c}0.012 \\
(0.008)\end{array}$ & $\begin{array}{c}-0.003 \\
(-0.002)\end{array}$ & $\begin{array}{c}0.063 \\
(0.051)\end{array}$ & $\begin{array}{l}-0.007 \\
(-0.001)\end{array}$ & $\begin{array}{c}0.045 \\
(0.031)\end{array}$ \\
\hline $\begin{array}{l}\text { Brightness } \\
\text { temperature (K) }\end{array}$ & $\begin{array}{l}-0.24 \\
(0.07)\end{array}$ & $\begin{array}{l}0.97 \\
(0.60)\end{array}$ & $\begin{array}{c}-0.07 \\
(-0.06)\end{array}$ & $\begin{array}{c}1.48 \\
(1.15)\end{array}$ & $\begin{array}{l}-0.13 \\
(-0.01)\end{array}$ & $\begin{array}{c}0.83 \\
(0.57)\end{array}$ \\
\hline
\end{tabular}

the northwestern corner of the granule; the fusion radiance is too low since sounder FOVs from farther away are used and the differences exceed 0.3 radiance units. Larger differences also occur when the coarser sounder spatial resolution is not able to capture small-scale radiance features (e.g., surface emissivity changes, cloud edges, and strong $\mathrm{H}_{2} \mathrm{O}$ gradients).

Overall, the constructed bands 25 and 35 (or band 33 as shown in Ref. 2) yield smaller errors than band 27, a $\mathrm{H}_{2} \mathrm{O}$-sensitive channel. Bands 25 and 35 are both $\mathrm{CO}_{2}$-sensitive bands with weighting functions that peak in the lower- to mid-troposphere. $\mathrm{CO}_{2}$ is considered a fairly well-mixed gas. Band 27 senses a spectral region sensitive to $\mathrm{H}_{2} \mathrm{O}$, which is not well mixed and indeed displays variability with height, and therefore provides different information (evident in Fig. 5) than the $\mathrm{CO}_{2}$ bands. Nevertheless, the fusion method seems to work reasonably well even for the more challenging water bands.

\subsection{VIIRS and CrIS Results}

VIIRS does not have any of the IR bands sensitive to atmospheric molecular absorption to support some applications such as determining accurate cloud-top heights and cloud phase. In the following, we show high spatial resolution IR absorption bands constructed using CrIS radiance information. VIIRS bands 15 and 16 (Table 1) of high and low spatial resolutions are used in the $\mathrm{k}-\mathrm{d}$ tree search. The radiance for these bands is shown in Fig. 7, for the same day and region as the MODIS granule (Figs. 3-6). Two 6-min granules are shown, namely those with measurement start times at 1436 and 1442 UTC.

From the k-d tree search, we obtain the indices of the five FOVs that are nearest in radiance and geolocation values. These indices are then applied to CrIS radiances convolved with the SRFs for MODIS bands 25, 27, and 35. The convolved CrIS radiances (at 14-km spatial resolution) are shown in the left column in Fig. 8, whereas the final VIIRS fusion radiance results at 750-m spatial resolution are shown in the middle column of Fig. 8. These results compare very well with the actual MODIS measurements, which are shown in the right

(a) VIIRS M15 radiance $\left[\mathrm{W} \mathrm{m}^{-2} \mathrm{sr}^{-1} \mu \mathrm{m}\right]$



(b) VIIRS M16 radiance [W $\left.\mathrm{m}^{-2} \mathrm{sr}^{-1} \mu \mathrm{m}\right]$



Fig. 7 VIIRS observed radiances for bands (a) M15 and (b) M16 on April 17, 2015 at 1436 UTC and 1442 UTC. 
Weisz, Baum, and Menzel: Fusion of satellite-based imager and sounder data to construct...

(a)



(b)

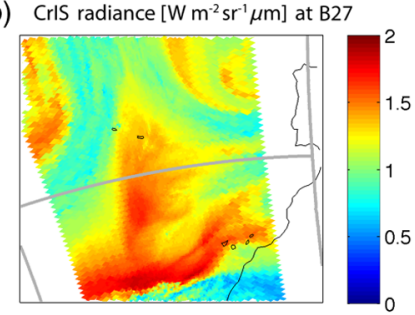

(c) CrIS radiance $\left[\mathrm{W} \mathrm{m}^{-2} \mathrm{sr}^{-1} \mu \mathrm{m}\right]$ at $\mathrm{B} 35$

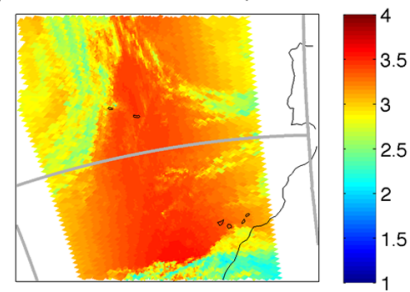

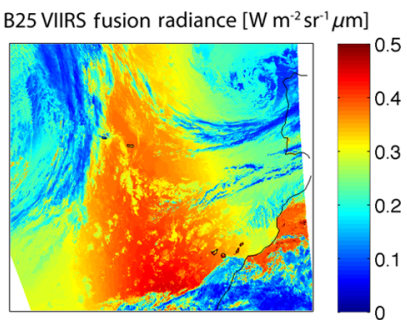

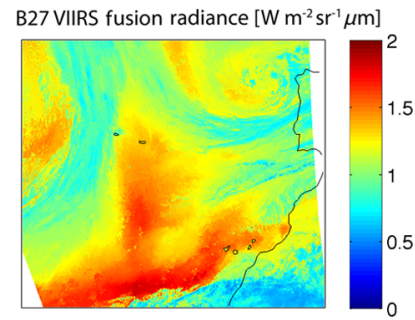

B35 VIIRS fusion radiance $\left[\mathrm{W} \mathrm{m}^{-2} \mathrm{sr}^{-1} \mu \mathrm{m}\right]$

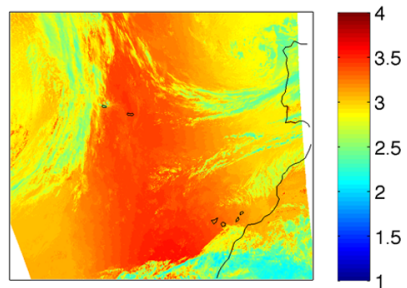

B25 MODIS radiance [W $\left.\mathrm{m}^{-2} \mathrm{Sr}^{-1} \mu \mathrm{m}\right]$

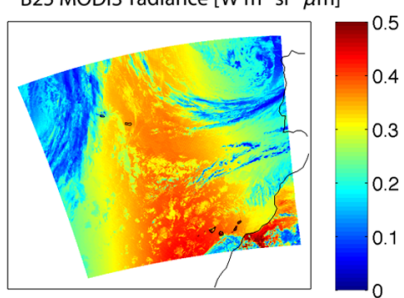

B27 MODIS radiance [W $\left.\mathrm{m}^{-2} \mathrm{sr}^{-1} \mu \mathrm{m}\right]$



B35 MODIS radiance $\left[\mathrm{W} \mathrm{m}^{-2} \mathrm{sr}^{-1} \mu \mathrm{m}\right]$

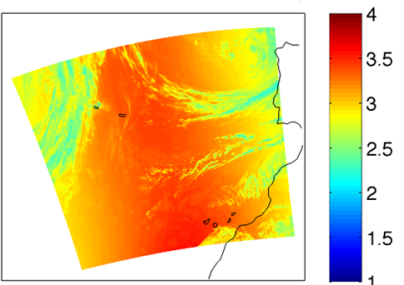

Fig. 8 Convolved CrIS radiances (left), newly constructed VIIRS fusion radiances (middle), and the observed MODIS radiances (right) for the same geographical region for MODIS bands 25, 27, and 35 in $(\mathrm{a}-\mathrm{c})$, respectively. VIIRS granule outlines are shown in gray in the left column.

column of Fig. 8 (also Fig. 6 on the left). Overall, the atmospheric $\mathrm{H}_{2} \mathrm{O}$ and cloud characteristics are reproduced closely in the fusion radiances. Again, the fusion results for band 27 [Fig. 8(b)] show more inaccuracies, because $\mathrm{H}_{2} \mathrm{O}$-sensitive channels sense different tropospheric regions than split-window channels. Also, small-scale and narrow spatial features in moisture (e.g., dry slots and cloud edges), which are not captured by the sounder due to its large spatial resolution, are more problematic for the fusion process. Furthermore, the results at the edge of the imager granule (i.e., outside the sounder swath) should be used with caution since they tend to be less accurate.

\subsection{Global Fusion Results}

The data fusion technique described above is fast and efficient; thus, it can be applied to large sets of data including data on scales appropriate for climate research. Global daytime fusion results are shown for one day (April 17, 2015) in Figs. 9-11. For each band, the MODIS observations, the MODIS “observed minus fusion" radiance differences, and the VIIRS fusion radiances are presented. The MODIS and VIIRS swaths have been limited to sensor zenith angles of $57 \mathrm{deg}$ and $60 \mathrm{deg}$, respectively, which roughly correspond to the limits of the sounder swath.

Overall, the MODIS differences for all bands are very small and display little bias. Note that there are no step changes when crossing land/ocean or snow/ice/ocean boundaries. When there are cloud $/ \mathrm{H}_{2} \mathrm{O}$ boundaries or regions with broken clouds or varying $\mathrm{H}_{2} \mathrm{O}$, there tends to be more variance in the radiance differences. Radiance differences are very low for large-scale features in both clouds and $\mathrm{H}_{2} \mathrm{O}$. The largest radiances differences can be found for the $\mathrm{H}_{2} \mathrm{O}$ band. Nevertheless, the high spatial detail of $\mathrm{H}_{2} \mathrm{O}$ and the cloud features notable in the MODIS observations (top of Figs. 9-11) is correctly reproduced by the VIIRS fusion radiance (bottom panels). To summarize, the data fusion approach is shown to provide reasonable construction of IR absorption bands with low overall biases but that may have higher "noise" regionally. 

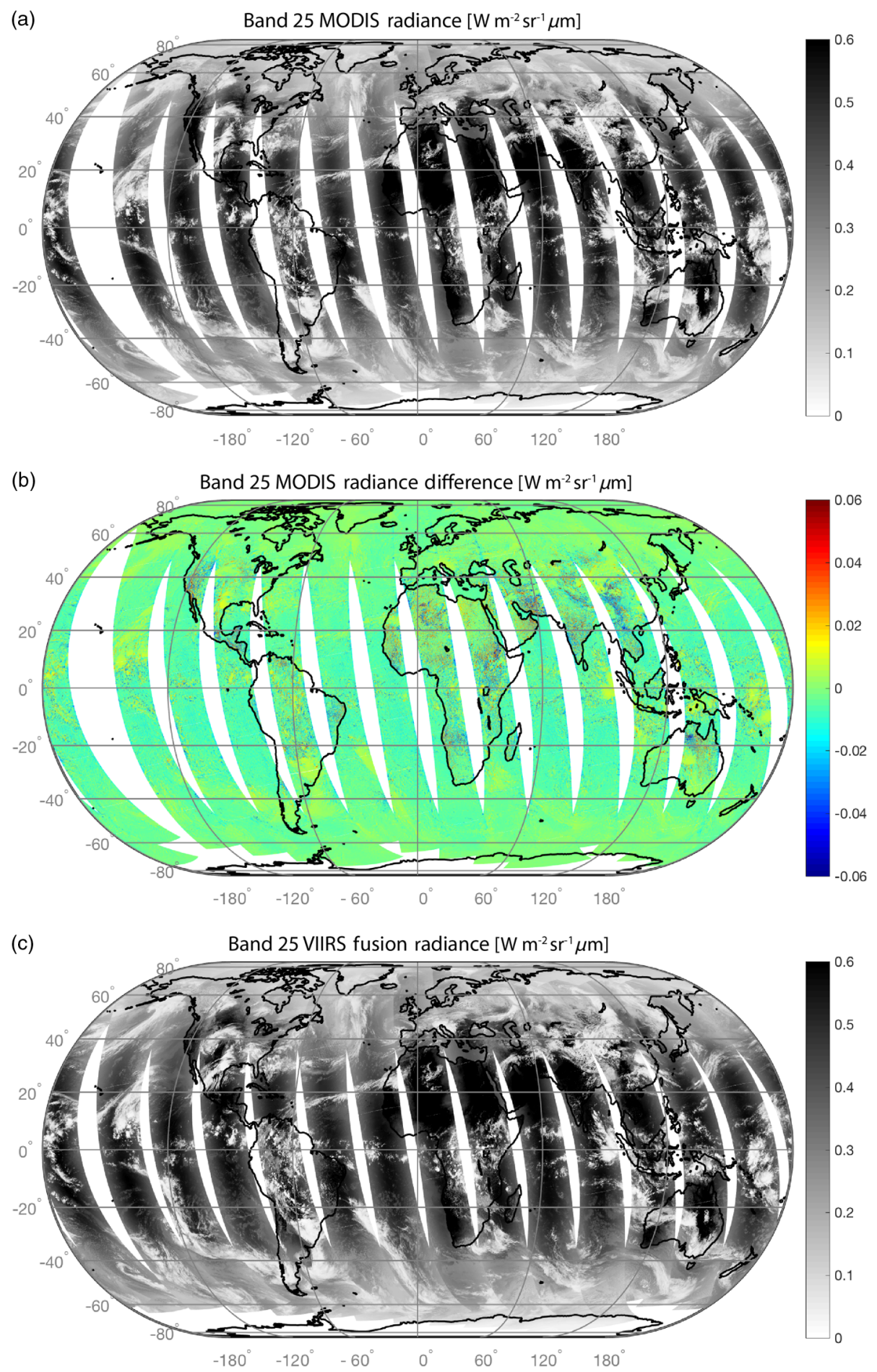

Fig. 9 (a) MODIS radiances, (b) the MODIS "observed minus fusion" radiance differences, and (c) the VIIRS fusion radiances for band 25 during daytime on April 17, 2015.

\section{Summary, Conclusions, and Future Work}

Unlike the MODIS instrument, the current generation imager VIIRS onboard Suomi-NPP does not provide measurements in the $\mathrm{CO}_{2}, \mathrm{H}_{2} \mathrm{O}$, and $\mathrm{O}_{3}$ absorption bands. But these observations are needed to accurately derive parameters such as $\mathrm{H}_{2} \mathrm{O}$ amount and cloud properties used in many applications including weather prediction, environmental monitoring, and climate trend research. In this study, we describe an imager/sounder data fusion technique to construct the 

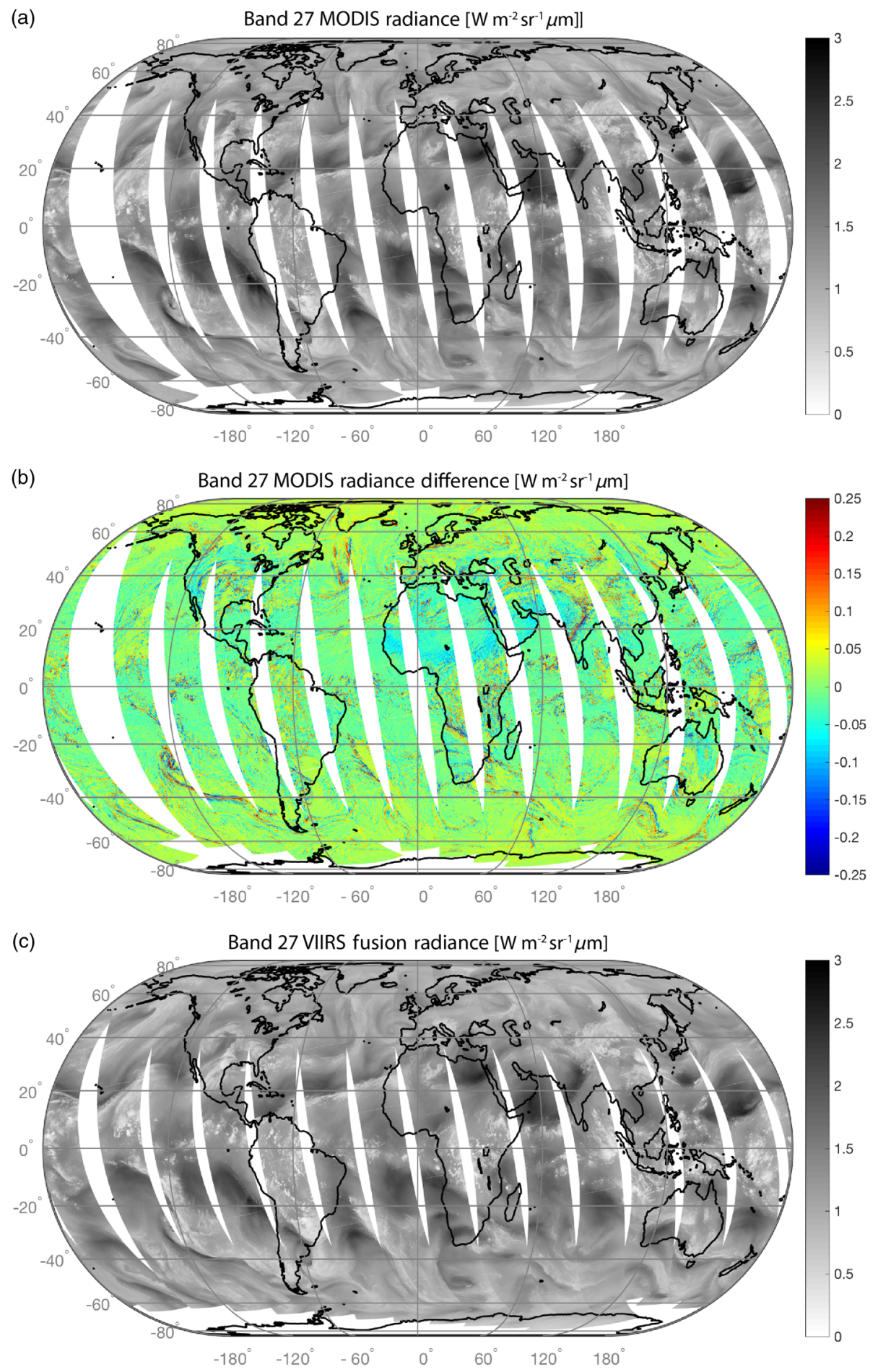

Fig. 10 (a) MODIS radiances, (b) the MODIS "observed minus fusion" radiance differences, and (c) the VIIRS fusion radiances for band 27 during daytime on April 17, 2015.

MODIS-like IR absorption bands for VIIRS at high spatial resolution with the help of CrIS. The first step of the technique is a nearest neighbor search using the k-d tree algorithm on split-window (i.e., 11 and $12 \mu \mathrm{m}$ ) imager radiances, which are given at high as well as at low spatial resolution (obtained by averaging all imager pixels within each sounder FOV). For each imager pixel, five sounder FOVs are identified as being the best match in radiance and location. In the second step, the sounder radiances, convolved using the desired SRFs for the imager band to be constructed, are averaged for the five FOVs for each imager pixel and these averages represent 



Fig. 11 (a) MODIS radiances, (b) the MODIS "observed minus fusion" radiance differences, and (c) the VIIRS fusion radiances for band 35 during daytime on April 17, 2015.

the new fusion radiances. Any MODIS band can be reconstructed for which the sounder contains radiance data; here, we present results for MODIS bands 25, 27, and 35 (centered at 4.5, 6.7, and $13.9 \mu \mathrm{m}$, respectively) to demonstrate shortwave, midwave, and longwave IR versatility as well as $\mathrm{CO}_{2}$ and $\mathrm{H}_{2} \mathrm{O}$ applicability. But in fact, the same approach could be applied to construct different IR absorption bands if so desired.

We present local and global results of the MODIS fusion reconstructed radiances and their differences to the actual observations. The differences are largest at the edge of the imager 
granule, since the sounder swath width is smaller than that of the imager. One of the primary deficiencies outside the sounder swath is that we have not corrected for the additional atmospheric absorption caused by the increased path length. By not correcting for the increased atmospheric absorption, the constructed radiances will be higher, and the "observed minus fusion" radiance differences with then be biased low. However, the differences within the sounder swath are small, and large-scale features are captured. Radiance differences tend to increase in regions of broken cloud or cloud edges. We also present VIIRS/CrIS fusion results and find good agreement between VIIRS fusion radiance and collocated in space and close in time MODIS radiance measurements.

The ability to estimate high spatial resolution radiances for any existing or newly desired IR absorption band from imager/sounder pairs offers new opportunities for retrieving accurate atmospheric and surface products and for studying their impact on operational and research applications.

In particular, the fusion results can also be used to supplement cloud products based on Suomi-NPP platform sensors. Ongoing work includes merging AVHRR and HIRS, as well as AVHRR and IASI. The former imager/sounder pair would allow supplementing the MODIS (on Terra and Aqua) cloud record with the NOAA cloud record. Fusing AVHRR with IASI (on Metop-A and Metop-B) will enable the extension of the MODIS record once Terra is no longer operational. An imager/sounder combination on different platforms (i.e., geostationary imager and polar-orbiting sounder) would also be worth investigating.

Another important task is to evaluate retrieval products (e.g., cloud and trace gas properties) derived from the imager/sounder fusion radiance estimates. Preliminary results confirm that the fusion estimates facilitate the retrieval of high-quality products of cloud-top pressure and IR thermodynamic phase. VIIRS/CrIS fusion products will therefore enable continuity of cloud records from the Terra and Aqua sensors. Further products to be investigated include tracking water vapor features to infer polar winds and detecting sulfur dioxide to locate volcano plumes.

Another topic for near-future investigation is the application of the fusion technique directly to hyperspectral retrieval products (instead to the convolved sounder radiance). For example, total precipitable water retrieved from hyperspectral sounder (AIRS, IASI, and CrIS) measurements could be provided at the imager's (MODIS, AVHRR, and VIIRS) high spatial resolution.

The implications for the design and spectral selection of future imager/sounder pairs on research and operational instruments remain to be determined, but it is very likely that these fusion results can influence the development of future weather satellite platforms. The pending studies suggested above will help to answer the broader implications of fusion enhancement of imager spectral coverage.

\section{Acknowledgments}

The authors gratefully acknowledge the support from NASA grant NNX14AP65A and the encouragement of Dr. Hal Maring (NASA Headquarters, Washington, D.C.). Conversations with Dr. Irina Gladkova (Department of Computer Science, City College of New York) were most helpful in developing the fusion technique for broader application. The collocation of imager pixels within the sounder field of view that is critical to the success of the fusion approach was performed by Greg Quinn and Fred Nagle (both UW-Madison/SSEC); we gratefully acknowledge their important contribution. We are also grateful to the reviewers for their helpful comments.

\section{References}

1. A. K. Heidinger et al., "Using CALIPSO to explore the sensitivity to cirrus height in the infrared observations from NPOESS/VIIRS and GOES-R/ABI," J. Geophys. Res. 115, D00115 (2010).

2. D. Klaes, F. Montagner, and C. Larigauderie, "Metop-B, the second satellite of the EUMETSAT polar system, in orbit," Proc. SPIE 8866, 886613 (2013).

3. J. I. Cross et al., "Statistical estimation of a $13.3 \mu \mathrm{m}$ visible infrared imaging radiometer suite channel using multisensor data fusion," J. Appl. Remote Sens. 7(1), 073473 (2013). 
Weisz, Baum, and Menzel: Fusion of satellite-based imager and sounder data to construct...

4. V. V. Salomonson et al., "MODIS: advanced facility instrument for studies of the earth as a system," IEEE Trans. Geosci. Remote Sens. 27, 145-153 (1989).

5. B. A. Baum et al., "MODIS cloud top property refinements for collection 6," J. Appl. Meteorol. Climatol. 51, 1145-1163 (2012).

6. H. H. Aumann et al., "AIRS/AMSU/HSB on the aqua mission: design, science objectives, data products, and processing systems," IEEE Trans. Geosci. Remote Sens. 41, 253-264 (2003).

7. B. H. Kahn et al., "The atmospheric infrared sounder version 6 cloud products," Atmos. Chem. Phys. 14, 399-426 (2014).

8. C. Cao et al., "Early on-orbit performance of the visible infrared imaging radiometer suite onboard the Suomi National Polar-Orbiting partnership (S-NPP) satellite," IEEE Trans. Geosci. Remote Sens. 52, 1142-1156 (2014).

9. H. Yong et al., "Suomi NPP CrIS measurements, sensor data record algorithm, calibration and validation activities, and record data quality," J. Geophys. Res. Atmos. 118, 12,73412,748 (2013).

10. J. L. Bentley, "Multidimensional binary search trees used for associative searching," Commun. ACM 18(9), 509-517 (1975).

11. R. Weber, H.-J. Schek, and S. Blott, "A quantitative analysis and performance study for similarity-search methods in high-dimensional spaces," in 24th Int. Conf. on Very Large Data Bases, New York, Vol. 98, pp. 194-205 (1998).

12. I. Gladkova et al., "Statistical estimation of a 13.3 micron channel for VIIRS using multisensor data fusion with application to cloud-top pressure estimation," in Proc. AMS 29th Conf. on Environmental Information Processing Technologies, Austin, Texas (2013).

Elisabeth Weisz received her MS degree in theoretical physics and her doctorate in geophysics and meteorology from the University of Graz, Austria. She has been with the Space Science and Engineering Center (SSEC) at the University of Wisconsin-Madison since 2001, currently serving as an associate scientist. Her research focuses on the development of atmospheric sounding retrieval algorithms using satellite-based high-spectral resolution infrared radiance measurements.

Bryan A. Baum received his doctorate in atmospheric sciences from the Georgia Institute of Technology in 1989. He is a senior scientist at the Space Science and Engineering Center at the University of Wisconsin-Madison, where he uses weather satellite data to study regional and global cloud properties and other phenomena. He previously worked in the Atmospheric Sciences Division at NASA Langley Research Center in Hampton, Virginia, USA, for over 16 years.

W. Paul Menzel received his degree in physics from the University of Wisconsin-Madison (UW) in 1974. Thereafter, at the UW SSEC, he explored possibilities for sounding the Earth's atmosphere from satellites. In 1983, he joined NOAA to develop and test new remote sensing environmental products. Currently a senior scientist at SSEC, he studies cloud and water vapor trends. He is a fellow of the American Meteorological Society. 